By WILLIAM L. EMERSON

\title{
Adequacy of Engineering
}

\section{Resources for Doctoral Research}

\section{In a University Library}

$\mathrm{S}$ INCE WORLD WAR II librarians have been aware of the problems caused by the vast growth of publication activities, particularly in the sciences. In terms of discussion, from Fremont Rider's The Scholar and the Future of the Research Library to the Allerton House Conference on Problems and Prospects of the Research Library, there has been concern with the organization and administration of research libraries as a consequence of this rapid growth. In terms of investigation, there has been during the past forty years a number of studies of various uses of library materials by research workers. ${ }^{1}$ One special type of study, however, that has been neglected is concerned with the problems of doctoral research. Only Swank's ${ }^{2}$ and a more recent unpublished dissertation by Stevens ${ }^{3}$ have dealt with the relation of library materials to doctoral research. These few studies have given libraries which are involved in supporting doctoral research programs little factual knowledge of the needs of re-

1 For an informative study of these surveys see: Rolland E. Stevens, Characteristics of Subject Liter. atures. ACRL Monographs, No. 6.

2 Raynard Coe Swank, "The Organization of Library Materials for Research in English Literature," Library Quarterly, XV (1945), 49-74.

3 Rolland E. Stevens, "The Use of Library Materials in Doctoral Research: A Study of the Effects of Differences in Research Methods." Urbana, Ill., 1951. 1491.

Mr. Emerson is head, Science and Technology Department, Long Beach Public Library. search workers. As Dunlap has pointed out, "The paucity of information regarding the needs and desires of readers has compelled librarians of institutions of higher learning to make decisions based on a number of widely accepted but unsubstantiated assumptions." 4

The only way to overcome a paucity of information is to gather some. This paper is concerned with the library needs of a small group of readers in a particular field in a university. It considers some of the characteristics of the literature used by doctoral candidates for their dissertations in engineering at Columbia University. It also shows to what degree the resources of the Columbia libraries were able to support these dissertations.

The major hypothesis underlying the study was suggested by "the widely accepted but unsubstantiated assumption" that scientific personnel, in general, primarily use recent material of serial nature in their research. In other words, the study hypothesized that doctoral research in some fields of engineering, as carried on at Columbia University over the past few years, primarily required recent material of a serial nature in the English language. By "recent" is meant material published within a five-year span of the date of the dissertation. Serial material was defined as, "a publication issued in successive parts, usually

\footnotetext{
"Leslie Dunlap, "Services to Readers," Library Trends, I (1952), 49.
} 
at regular intervals, and, as a rule, intended to be continued indefinitely." 5 This was in opposition to monographic material, which was defined as, "a systematic and complete treatise on a particular subject, usually detailed in treatment but not extensive in scope." 6 In addition to identifying these two major characteristics of the literature cited, this study includes an analysis of some of the other features. Each of these two major groups will be identified as to general type of publisher, i.e., a commercial or trade publication, a publication of one of the engineering or other learned or professional societies, a governmental agency publication, a university publication, or a publication of an industrial concern. Secondly, the language factor and the time span of these materials are analyzed. Such an analysis of the literature might enable the Engineering Library to ascertain how its collection could be organized to serve this portion of its users.

The basic assumption of the study was that the items listed in the bibliographies of the dissertations in question would reveal the materials used by the researcher. The methodology was to list on a separate punched card each item listed in these bibliographies. These cards were coded for the factors listed above, and a statistical analysis was made.

The dissertations studied were taken from those dated over the years 1950-54. This would seem to give an adequate sampling of the type of research on the doctoral level done in these fields at Columbia. The field of chemical engineering was not included, as such material is primarily the concern of the Chemistry Library. There were twenty-three dissertations listed in the years under study. They fell into the following subfields:

'ALA Committee on Library Terminology. ALA Glossary of Library Terms With a Selection of Terms in Related Fields. (Chicago, ALA, 1943), p. 124.

Ibid. p. 88 .
Electrical engineering .... 9

Mechanical engineering ... 6

Civil engineering ....... 7

Mineral engineering ...... 1

23

Since there was only one dissertation in the field of mineral engineering, it was included as part of the sample, but the evidence of the material within the dissertation should be taken as only possibly indicative of the field. For the twenty-three dissertations, there was a total of 761 citations. A total of 756 could be sufficiently identified to warrant inclusion in the study. This gave an arithmetic mean of 38.8 citations per dissertation. The breakdown of the number of citations per dissertation by fields was as follows: Electrical engineering, 43.9; Mechanical engineering, 38.5; Civil engineering, 14.7; Mineral engineering, 27.0 .

The major breakdown of the citations between serial material and monographic material revealed that 70.9 per cent of the citations was for serials and 29.1 per cent for monographs. The breakdown within the fields showed the following variations:

\section{Mono- \\ Serials graphs \\ (Per Cent) (Per Cent)}

$\begin{array}{lll}\text { Electrical engineering } & 78.4 & 21.6 \\ \text { Mechanical engineering } & 65.8 & 34.2 \\ \text { Civil engineering } & 53.3 & 46.7 \\ \text { Mineral engineering } & 66.6 & 33.3\end{array}$

Since there are no comparable data in this or any other field, it is not known if the variations within the field presented here are typical or atypical. That there was this variation within the engineering field suggests hypotheses which might be tested to answer the question. These will be discussed later. The general findings in this respect tend to bear out part of the major hypothesis being tested.

Serials seem to be the primary source 
TABLE I

Publication Sources of Monographic Material (Per Cent)

\begin{tabular}{|c|c|c|c|c|c|}
\hline & Commercial & Society & Governmental & University & $\begin{array}{l}\text { Industrial } \\
\text { Company }\end{array}$ \\
\hline Electrical engineering. & 70.9 & 3.3 & 2.3 & 18.9 & 4.6 \\
\hline Mechanical engineering ........ & 78.5 & 2.5 & 5.1 & 13.9 & 0 \\
\hline Civil engineering ......... & 66.6 & 27.1 & 0 & 0 & 6.3 \\
\hline Mineral engineering & 88.8 & 0 & 0 & 11.2 & 0 \\
\hline Mean for group ......... & 73.4 & 2.4 & 2.7 & 12.6 & 3.1 \\
\hline
\end{tabular}

TABLE II

Publication Sources of Serial Material (Per Cent)

\begin{tabular}{|c|c|c|c|c|c|}
\hline & Commercial & Society & Governmental & University & $\begin{array}{l}\text { Industrial } \\
\text { Company }\end{array}$ \\
\hline Electrical engineering . & 27.7 & 52.4 & 2.2 & 2.9 & 14.8 \\
\hline Mechanical engineering $\ldots \ldots \ldots \ldots \ldots$ & 34.1 & 48.1 & 11.1 & 4.6 & 2.1 \\
\hline Civil engineering $\ldots \ldots \ldots$ & 0 & 78.0 & 3.9 & 16.3 & 1.8 \\
\hline Mineral engineering $\ldots \ldots \ldots \ldots \ldots$ & 5.6 & 88.9 & 5.5 & 0 & 0 \\
\hline Mean for group $\ldots \ldots \ldots \ldots \ldots \ldots$ & 26.5 & 54.3 & 5.2 & 4.6 & 9.3 \\
\hline
\end{tabular}

TABLE III

Language Distribution (Per Cent)

\begin{tabular}{|c|c|c|c|c|}
\hline & English & German & French & Other \\
\hline Electrical engineering. & 77.8 & 11.8 & 6.2 & 4.1 \\
\hline Mechanical engineering & 75.2 & 14.4 & 7.1 & 3.2 \\
\hline Civil engineering $\ldots \ldots$ & 84.4 & 7.5 & 1.5 & 6.5 \\
\hline Mineral engineering $\ldots .$. & 100.0 & 0 & 0 & 0 \\
\hline 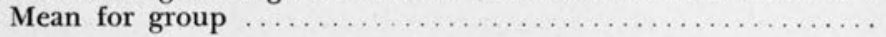 & 80.8 & 11.7 & 6.1 & 1.2 \\
\hline
\end{tabular}

in supporting doctoral research in certain fields of engineering at Columbia University. This type of material constitutes from slightly more than half in the case of civil engineering to more than three-quarters of the material in the case of electrical engineering, with an arithmetic mean of 70.9 per cent for the group as a whole. This would substantiate claims made for the importance of this type of material in the engineering field.

At this point, it is possible to analyze the publication sources for the materials used in these dissertations. Tables I and II identify the type of publisher and show the percentile ratings for each group in each of the engineering fields studied. The mean is given for the group as a whole.

From Tables I and II it can be seen that commercial, or trade, publications for the monographs, and society publications for the serials are the two major publishing sources for the literature cited in these dissertations. If it is remembered that serials accounted for 70.9 per cent of the citations, it can be said that serial publications of societies are the single most cited group. Again it is to be noted that considerable variations are found among the fields studied.

The next major characteristic analyzed was the language distribution of the citations. Since this factor operated 
independently of the type of material cited, no breakdown was made between serials and monographs in this group. Table III shows the language distribution of the citations.

It should be pointed out that the mineral engineering sample included only one dissertation. The languages in the "Other" column were Russian, in the case of mechanical engineering, and Italian, in the cases of electrical and civil engineering. These languages occurred in single dissertations within these fields rather than being distributed throughout the group. French and German, on the other hand, occurred throughout the sampling in the three fields. In all cases, it can be seen that German is the second largest language cited although it falls far below English.

There is finally to be considered the time span of the material used in these dissertations. A check analysis of the material revealed that both monographic and serial materials were falling into a similar pattern; so both types were analyzed together. Table IV shows the findings.

The results presented in Table IV test the other major section of the basic hypothesis. From the evidence presented, it can be seen that this part of the hypothesis is not as true as that concerning the relative importance of serial and monographic material. Less than half of the cited material fell into the $0-5$ year span, which was taken to be recent by arbitrary definition. A more correct restatement in this connection would be that although the largest single percentile group will probably be found in material of recent date, there will be a wide range of material considerably older.

Since almost 15 per cent of the material fell into the category, "Over 25," a separate run was made of this group. The findings revealed that in all of the fields represented some of the material used was between 25-50 years old. In me- chanical and civil engineering fields, some material used was between 51-100 years old, and a scattering of material was over a hundred years old. However, the materials for "Over 50" were concentrated in one dissertation in each of these fields rather than being distributed throughout the field. These particular dissertations dealt with the historical development of the particular problem under study.

In general, then, the characteristics of the research literature cited in these dissertations revealed that English language serial material, particularly the publications of the various engineering societies, forms the major group numerically. A detailed profile of the literature cited shows a wide diversity in time as well as in form. German and French are the major foreign languages.

It is now possible to turn to the citations and analyze them in terms of actual titles used. The 534 serial citations covered 181 serial titles. The arithmetic mean for the ungrouped data gives an average of 3.38 citations per title. This, however, is rather misleading, because when the scores are grouped into a frequency distribution, the median becomes .88 citations per title. This large differential is owing to the fact that of the 181 serial titles, 102 , or 56.3 per cent, were cited only once; 59 titles, or 32.5 per cent, were cited between 2 and 5 times and only 20 of the titles, or 11.1 per cent, were cited more than five times. The implications of this tend to bear out the fact that researchers on a doctoral level must, in general, have access to a wide variety of resources. There will be a core of basic material, but the pattern revealed by this analysis is that there must be a large fringe of material less often used but which contributes to doctoral research. Along with this pattern, there was a pronounced tendency for any given dissertation to show a high citation count for a particular serial title. At least four of the serial titles which had 
TABLE IV

Time-span of Material Cited (Per Cent)

\begin{tabular}{|c|c|c|c|c|c|c|}
\hline & $\begin{array}{c}0.5 \\
\text { Years }\end{array}$ & $\begin{array}{l}6-10 \\
\text { Years }\end{array}$ & $\begin{array}{l}11-15 \\
\text { Years }\end{array}$ & $\begin{array}{l}16-20 \\
\text { Years }\end{array}$ & $\begin{array}{l}21-25 \\
\text { Years }\end{array}$ & $\begin{array}{c}\text { Over } 25 \\
\text { Years }\end{array}$ \\
\hline Electrical engineering & 58.4 & 14.9 & 9.4 & 7.8 & 6.3 & 3.2 \\
\hline Mechanical engineering ....... & 27.3 & 15.2 & 13.9 & 5.6 & 8.2 & 29.8 \\
\hline Civil engineering $\ldots \ldots \ldots \ldots \ldots$ & 35.9 & 12.8 & 10.6 & 8.7 & 5.8 & 26.2 \\
\hline Mineral engineering ......... & 55.5 & 14.8 & 7.4 & 0 & 14.8 & 7.4 \\
\hline Mean for group $\ldots \ldots \ldots \ldots \ldots$ & 45.5 & 14.7 & 10.6 & 7.0 & 7.1 & 14.7 \\
\hline
\end{tabular}

a frequency citation of ten or more were all from single dissertations. This again is possibly a normal pattern, but no comparable findings are available to test such a hypothesis.

A similar pattern was found when the monograph citations were analyzed. The 222 monograph citations were produced by 192 titles. Of these titles, 181, or 94.2 per cent, were cited only once. Eight titles were cited twice, two titles were cited three times, and only one title was cited four times. No title among the monographs was cited more than four times. On the basis of this sampling, it might be possible to state that so far as monographic literature is concerned, for the studies in these fields of engineering, there was no heavily used core. The title which was cited four times was Kent's Mechanical Engineers' Handbook, a standard reference source.

One other aspect of the general pattern of literature cited might be mentioned. There was a decided tendency for each of the engineering fields to be somewhat autonomous as far as the materials used were concerned. Only one serial title was common to all four fields. Of the 181 serial titles, 155 , or 85.6 per cent, were cited in one field alone. Twenty titles were cited in two fields and five titles were cited in three fields. The same pattern was even more pronounced for monographic literature. Only Kent was cited in more than one field. There is probably a correlation between this factor and the pattern discussed previously for each dissertation to show a high citation count from any one or two of the serial titles. There is the further possibility that self-citation in the serials concerned might be a causal factor in this regard.

The foregoing analysis of the characteristics of the literature cited in these engineering dissertations tends to bear out the hypothesis relating to the relative importance of serial material for this field of applied science. However, there was a considerable spread in time for this material although the largest single percentile group was in the $0-5$ year time span. English is the primary language, followed by German and French. There was present a smaller citation group from other foreign languages. It is difficult to say whether this was the result of a lack of facility in these languages or the absence of relevant materials. Finally, there was the tendency of each of these fields of engineering to develop to a large extent a literature of its own with little or no overlapping with the other fields.

The analysis of these findings gives rise to further hypotheses which might be tested in terms of other, or larger, universes. It might be worth while to find out if the tendency of these subgroups within the engineering field is common to engineering doctoral work in general or is simply a local characteristic. It might also be interesting to see if this same pattern is present in other disciplines, and, if so, to what degree. Lastly, it would be extremely useful to establish workable parameters for the establishment of what constitutes a "core" collection needed to support doc- 
toral research in any given field. If such parameters could be established, it might be possible to work out mathematical models for such collections. More will be said on library support of doctoral research at a later point.

It is now possible to turn to the second major aspect of this study, which deals with Columbia library resources and the degree to which they were able to provide support for the literature needed in this group of engineering dissertations. Because of the proportionate importance of serial materials, they have been analyzed a little more thoroughly in this respect than the monographic material. Since these dissertations were of very recent years, only a spot check was made to see if the materials were actually available when the work was being done. Such a check showed that the material in the libraries used on these dissertations was available at the time of study. Of the 192 monographic titles, the Engineering Library held 64.2 per cent, including all of the titles cited more than once. Other libraries on campus, mainly the Physics and Chemistry libraries, held an additional 21.8 per cent of these titles. Of the 192 monographic titles cited, 14 per cent were not available at Columbia. Thirteen of these lacking titles were foreign publications, including two foreign dissertations. No check was made to see if this monographic material was available elsewhere in the New York area.

Of the 181 serial titles listed, the Engineering Library held 93 , or 51.3 per cent. Other libraries on campus, mostly the various science libraries, held an additional 49 , or 27.1 per cent. Of the 181 serial titles cited, 39, or 21.5 per cent, were not available at Columbia. In view of the fact that serials represent a more important source for doctoral study than monographs, the fact that Columbia showed up less well in its support of the serials than of the monographs might be worth a few remarks. At this point, only one or two possibly causal factors might be mentioned. The book budget for the Engineering Library is weighted roughly about 67 per cent for serials and about 33 per cent for monographs. This is fairly close to, but falls at little below, the corresponding weights for serials and monographs as used by the dissertations studied which, it will be recalled, were 70.9 per cent for serials and 29.1 per cent for monographs. It seems that the primary factor to be considered in this regard is that the Engineering Library, out of its book funds, must support various groups of users. It would be useful to try to find the comparative use of library materials by these various groups, the undergraduates, the graduates, the faculty, and others. Once this information was procured, some method of determining a value judgment among these groups might be worked out and available book funds prorated accordingly.

To return to the analysis of serial material, it is worthwhile noting that Columbia was able to supply all of the serials which were common to more than one dissertation. Some additional aspects of this serial material should be mentioned. Of the 181 serial titles cited, 57.6 per cent were indexed in the Engineering Index, and 15.7 per cent were indexed in Industrial Arts Index. Of these titles, the Industrial Arts Index did not list any title which was not listed in the Engineering Index. Of the 39 titles which Columbia did not have, only 7, or 17.6 per cent, were in the Engineering Index. This fact might tend to support an hypothesis that the serial material which was not available at Columbia was generally of less importance to the field of engineering itself.

The titles lacking were too diverse to draw any single significant conclusion relating to their absence from Columbia's resources. The major factor they had in common was that 24 of them, or

(Continued on page 504) 


\section{Adequacy of Engineering Resources}

(Continued from page 460)

61.5 per cent, were foreign publications. Also it might be pointed out that 11, or 28.2 per cent of these missing titles were listed in the Union List of Serials as being at the Engineering Societies Library. However, it should be added that a complete comparative run of the serial titles was not made, and it is possible that the Engineering Societies Library mght show an equal or greater percentage of titles unavailable.

The total number of titles, both serial and monographic, which was used on these dissertations, was 373 . Of this total, 66 , or 17.6 per cent, were unavailable at Columbia. There are no comparable data to show if this is particularly high, low, or a possible median figure. The only findings which are at all relevant are those compiled by Stevens. He studied one hundred dissertations done in five fields at three universities. The fields were American History, Classical Languages and Literature, Education, Botany, and Psychology. He sorted the dissertations according to the basic methodology employed, i.e., historical, textual, and experimental. The following table is taken from his dissertation. ${ }^{7}$

$\begin{array}{lc}\begin{array}{c}\text { Type of } \\ \text { Dissertation }\end{array} & \begin{array}{c}\text { Per Cent Not } \\ \text { in Libraries }\end{array} \\ \text { Historical } \ldots \ldots \ldots & 41.36 \\ \text { Textual } \ldots \ldots \ldots \ldots & 21.59 \\ \text { Experimental } \ldots \ldots & 11.52 \\ \text { OP. cit., leaf } 30 .\end{array}$

The engineering dissertations studied do not fall neatly into any one of these categories. It is possible that the majority of them might be classified as experimental in nature, but at least two would overlap into the historical. There are too many variables existing between this study and Stevens's much more comprehensive one to make the figures he gives more than merely analogous. In view of his findings, though, it is probable that an assumption might be warranted that no university library collection canor even should-supply 100 per cent of the materials used in doctoral research. Here again is a topic for further study. What degree of support is given at Columbia in other disciplines in research on the doctoral level?

The figures gleaned in this study showing Columbia could not supply 14 per cent of the monographic titles and 21.5 per cent of the serial titles cited in these twenty-three recent dissertations. If enough such "bits" of information can be secured, Columbia would have some quantitative criteria for the evaluation of its collection, at least insofar as its ability to support doctoral research is concerned. If, on the other hand, other libraries which must render support to doctoral research in the fields of engineering covered in this study could gather similar data, a set of standards for resources in these fields could be set up as a measuring device.

\section{Membership Vote Cancels Council on Move}

The mail vote of ALA membership determined that ALA Headquarters will not remove to Washington, D. C., as the Council voted in June at the ALA Conference in Kansas City. The vote was 5,749 to set aside the Council action, 2,199 to sustain the action. Under the ALA Constitution, at least one quarter of the membership had to participate in the vote. ALA's total membership is about twenty thousand. 